\title{
Energy characteristics of self-healing process in metallized film capacitors
}

\author{
Victor Belko ${ }^{1}$, Ivan Ivanov ${ }^{1, *}$, Andrey Plotnikov ${ }^{1}$, and Valery Belanov ${ }^{2}$ \\ ${ }^{1}$ Peter the Great St. Petersburg Polytechnic University, 195251, Russia, St. Petersburg, Polytechnicheskaya 29 \\ ${ }^{2}$ Finotec Oy, PL 115, 45101 Kouvola, Finland
}

\begin{abstract}
Metallized film capacitors widely used in energy applications were studied. The experimental method for investigation of energy and dynamic characteristics of self-healing processes in real metal-film capacitors was developed. The commercial PET and PP MFCs of $0.22-1 \mu \mathrm{F}$ capacitance and $63-250 \mathrm{~V}$ voltage were tested. Depending on applied voltage, 3 types of SH processes in MFC were discovered: single, repetitive, and multiple SH. Dependencies of self-healing energy on breakdown voltage were obtained. These dependencies are described by power law with the exponent $n=2.2-2.4$ that significantly differs from literature data. The obtained data will be used for degradation and aging laws formulation for capacitors' energy storage capability improvement.
\end{abstract}

\section{Introduction}

Metallized film capacitors (MFC) are used in a wide variety of applications, such as power factor correction, energy storage, power electronics, including EMI filtering, renewable energy sources and hybrid/electric vehicles power systems (for DC filtering between rectifier and inverter in automotive applications) [1-5].

MFCs consist of dielectric films (most commonly polypropylene (PP) or polyethylene terephthalate (PET)) with a metallic coating on the surface. Thus, the electrodes are presented by very thin layers $(5$ to $50 \mathrm{~nm}$ ) of metal, usually aluminum or zinc, evaporated onto the surface of the polymer film. Thin metallization provides these MFCs with a unique self-healing (SH) property. Due to occasional overvoltages, aging and polymer film defects the electrical breakdown of capacitor dielectric is possible. When the breakdown occurs, high density current flows through the breakdown channel. Due to small thickness the metallized layer around the breakdown channel evaporates. This process lasts tens microseconds. Demetallized area on the surface of the polymer films prevents secondary breakdown in this point, so the breakdown strength of the capacitor restores. The similar situation in conventional metal foil/polymer film capacitor doubtlessly leads to short circuit of the terminals with subsequent heating and even explosion.

SH allowed increasing the values of electric field in capacitors since tens to hundreds of $\mathrm{kV} / \mathrm{mm}$ that leads to better specific energy characteristics. In the case of lowvoltage capacitors $\mathrm{SH}$, demetallized area is quite small (units of $\mathrm{mm}^{2}$ ), so tens and even hundreds of SHs do not affect the capacitance and reliability of capacitors. One of the main parameters of SH process is an energy dissipated during one SH act. At high values of capacitor voltage (more than $1 \mathrm{kV}$ ) or capacitance (hundreds $\mu \mathrm{F}$ ), the dissipated energy reaches dangerous level and may lead to the failure of the capacitor [6].

In order to limit SH energy two metallization technologies exist: thickness structured metallization (2$5 \mathrm{~nm}$ ultrathin layer, variable profile) and surface structured metallization. Small demetallization areas and low SH energy values are typical for the first type of structured metallization, however very high surface resistance of ultrathin electrodes (100 - 300 Ohms per square) leads to increasing of capacitors' ESR value and losses and limits their application. Second type of structured metallization is segmented. In this metallization the surface is divided into segments ( $\mathrm{T}$ - or mosaic patterns) interconnected by narrow bridges which act as fuses in the case of breakdown. During the SH the defected segment is cut off the rest part of the electrodes. Geometric parameters of intersegment bridges have to be properly designed in order to minimize the bridge destruction time and thus limiting the SH energy [7-8].

Limited (or controlled) SH energy is the key to development of energy efficient, weight- or costeffective capacitors for industrial applications with weight and space limitations (electric vehicles, space and military purposes [9]). The SH process is governed by several factors, such as capacitor's voltage and capacitance, metallization thickness and structure, polymer nature and others. They have been investigated

\footnotetext{
*orresponding author: ivanov.eicc@yandex.ru
} 
since 1970s [10] and still are the matter of interest [1113].

Voltage across the capacitor determines electric field in the polymer film and thus energy stored in the capacitor. Doubling the capacitor`s voltage $U$ leads to 4 times increase of its stored energy $W$ :

$$
W=\frac{C U^{2}}{2},
$$

where $C$ is a capacitance.

However, high voltage also causes high and dangerous SH energy. Moreover, higher SH energy leads to higher demetallized area and its stronger carbonization. Thin graphite layer is a result of cooling of the gas phase formed by decomposition of thin layer of the polymer film during SH [14]. This graphite layer contributes to a total decrease of insulation resistance another important characteristic of capacitor determining its dissipation factor. The design of the energy efficient MFC requires taking into consideration the correlation between capacitor voltage and SH energy since it can be put in the base of the capacitors' aging law [6].

As it was shown by numerous $\mathrm{SH}$ process investigators, the $\mathrm{SH}$ energy $\left(W_{S H}\right)$ value depends on MFC breakdown voltage $(U)$ in accordance with power law (see the Table 1).

Table 1. SH process characteristics obtained previously.

\begin{tabular}{|c|c|c|c|c|c|c|c|}
\hline & $\begin{array}{c}\text { SH } \\
\text { duration }\end{array}$ & $\begin{array}{c}\text { Experim. } \\
\text { voltage }\end{array}$ & $\begin{array}{c}\text { Temp. in } \\
\text { SH area }\end{array}$ & $\begin{array}{c}\text { Extinction } \\
\text { criteria }\end{array}$ & $\begin{array}{c}W_{S H^{\sim}} \mathbf{U}^{n}, \\
\boldsymbol{n}=\end{array}$ & $\begin{array}{c}\text { SH duration } \\
\text { depends on }\end{array}$ & $\begin{array}{c}\text { SH } \\
\text { effectiveness } \\
\text { criteria }\end{array}$ \\
\hline Klein [15] & ns, $\mu \mathrm{s}$ & - & $\begin{array}{c}4000- \\
4500 \mathrm{~K}\end{array}$ & $\begin{array}{c}\text { Critical } \\
\text { energy }\end{array}$ & - & - & - \\
\hline $\begin{array}{c}\text { Heywang } \\
{[10]}\end{array}$ & - & $<300 \mathrm{~V}$ & $<8000 \mathrm{~K}$ & - & 4.7 & - & $h_{\text {graphite }}$ \\
\hline $\begin{array}{c}\text { Kamermaier } \\
{[16-17]}\end{array}$ & - & - & $4300 \mathrm{~K}$ & $\begin{array}{c}\text { Critical } \\
\text { energy }\end{array}$ & 4 & $U$ & $h_{\text {graphite }}$ \\
\hline $\begin{array}{c}\text { Tortai [18- } \\
\text { 20] }\end{array}$ & $\mu \mathrm{s}$ & $<500 \mathrm{~V}$ & $7000 \mathrm{~K}$ & $\begin{array}{c}\text { Critical } \\
\text { power }\end{array}$ & 6 & - & - \\
\hline $\begin{array}{c}\text { Christen, } \\
\text { Carlen [21] }\end{array}$ & $\mu \mathrm{s}$ & $<3 \mathrm{kV}$ & $>5000 \mathrm{~K}$ & - & - & - & - \\
\hline \begin{tabular}{l} 
Belko [22] \\
\hline
\end{tabular} & $\mu \mathrm{s}$ & $<300 \mathrm{~V}$ & - & $\begin{array}{c}\text { Critical } \\
\text { power }\end{array}$ & 6.1 & $U$ & - \\
\hline
\end{tabular}

Most of the data presented in Table 1 was obtained on capacitor models (stacked samples of metallized polymer films, sometimes with initial defects). Meanwhile, the preliminary experimental results let us conclude that exponent $n$ in $W_{S H} \sim U^{n}$ equation is significantly lower for $\mathrm{SH}$ processes in real capacitors. It is very important for the degradation behavior study and correct estimation of capacitor reliability and lifetime.

The aim of this research is development of the method of $\mathrm{SH}$ process investigation in real capacitors and establishing the correlation between voltage and $\mathrm{SH}$ energy for correct estimation of capacitor reliability and lifetime.

\section{Methods}

Commercial PET and PP MFCs were investigated. Capacitance and voltage were in the range of $0.22-1 \mu \mathrm{F}$ and $63-250 \mathrm{~V}$ respectively. Simplified scheme of experimental circuit is shown in Fig. 1. The main elements of experimental circuit were DC high voltage power supply, resistive-capacitive voltage divider, experimental cell and oscilloscope unit. The power supply consisted of adjustable high voltage transformer, half-wave rectifier and capacitive filter.
The voltage across the testing capacitor $C_{x}$ was raised stepwise (30 - $50 \mathrm{~V}$ step) with hold time $\sim 1$ minute per step. The voltage was measured by resistive-capacitive voltage divider and 2-timescale oscilloscope scheme. Such scheme was necessary for synchronous measuring of fast voltage drop during $\mathrm{SH}$ and slow process of voltage restoring. Typical voltage waveforms are shown in Fig. 2.

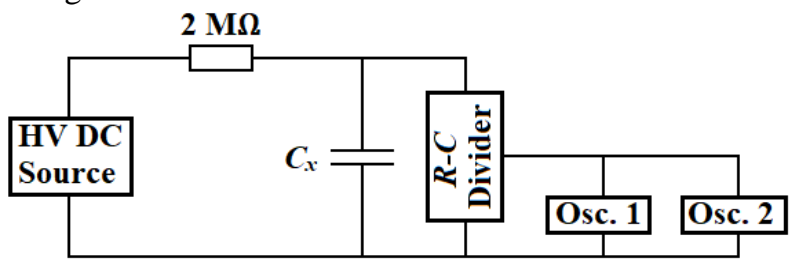

Fig. 1. Simplified scheme of experimental circuit 


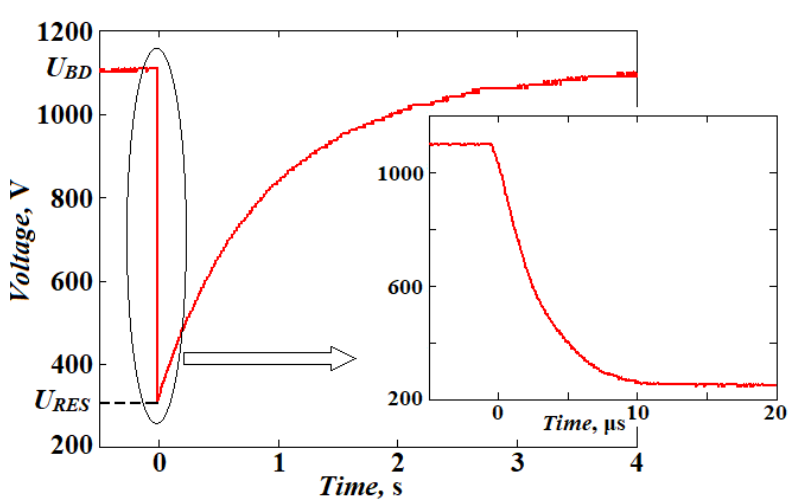

Fig. 2. Typical voltage waveforms during SH process

Using segmented memory of digital oscilloscopes made it possible to save continuously all oscillograms and use it in the post processing. It is assumed that capacitance decreasing of testing capacitors after one $\mathrm{SH}$ act is negligible. Then the SH energy is:

$$
W_{S H}=\frac{C_{X}\left(U_{B D}^{2}-U_{R E S}^{2}\right)}{2},
$$

where $C_{X}$ is capacitance of testing capacitor, $U_{B D}$ is breakdown voltage, $U_{R E S}$ is residual voltage (Fig. 2).

The current waveforms were calculated using experimental dependencies of capacitor`s voltage during SH as:

$$
I_{S H}(t)=-C_{X} \frac{d U(t)}{d t} .
$$

\section{Results and Discussion}

It was found that different types of $\mathrm{SH}$ process are possible. Depending on voltage level, there were 3 types of $\mathrm{SH}$ :

- $1^{\text {st }}$ - single SH (less than $3-4 U_{\text {nom }}$ );

- $2^{\text {nd }}$ - repetitive SH $\left(4-6 U_{\text {nom }}\right)$;

- $3^{\text {rd }}$ - multiple SH (more than $6 U_{\text {nom) }}$.

$U_{\text {nom }}$ is a nominal voltage. The examples of possible $\mathrm{SH}$ types are shown in Fig. 3.

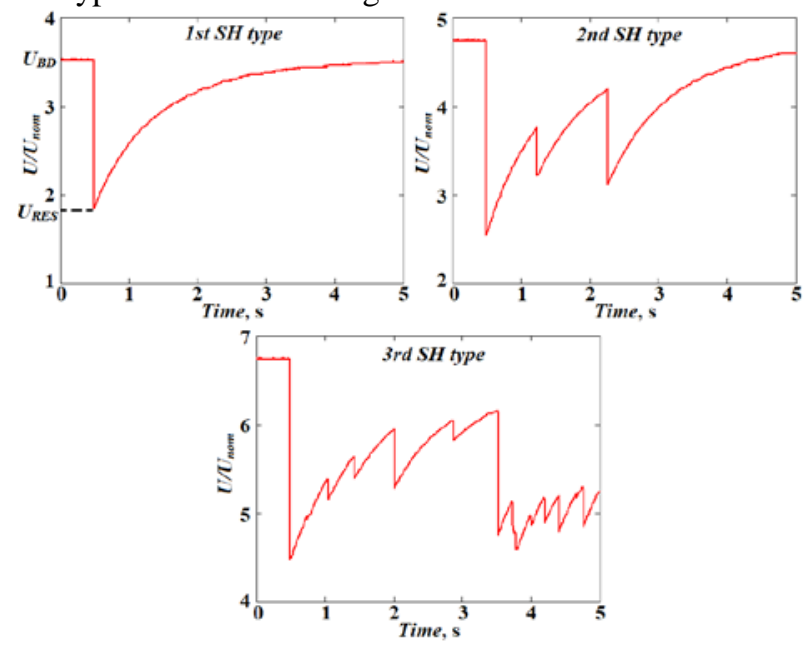

Fig. 3. Different types of SH process
In the case of the single $\mathrm{SH}$ process there was a fast decreasing of capacitor`s voltage by $30-60 \%$. After that capacitor's voltage restored. The repetitive $\mathrm{SH}$ process was characterized by $2-4$ repeating $\mathrm{SH}$ acts during voltage restoring. The correspondent current waveforms are presented in Fig. 4.
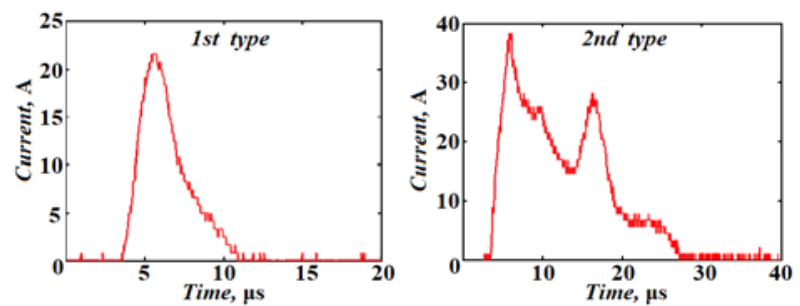

Fig. 4. Current waveforms during $\mathrm{SH}$

The $1^{\text {st }}$ type corresponded to the single dielectric breakdown and there was only 1 peak on the dependence $I(t)$. In the case of the $2^{\text {nd }}$ type there were 2 and more current peaks that corresponded to several consequent dielectric breakdowns.

In the $3^{\text {rd }}$ type $\mathrm{SH}$ process the uncontrolled multiple series of SH acts was observed. After capacitor`s voltage level reached the value of $7-8 U_{\text {nom }}$, the capacitor`s failure was observed. It was characterized by dramatic decreasing of insulation resistance and capacitance.

The important characteristic of $\mathrm{SH}$ process is a dependence of SH energy $W_{S H}$ on breakdown voltage $U_{B D}$. In the Fig. 5 typical $W_{S H}\left(U_{B D}\right)$ dependencies for capacitors of different dielectric, capacitance and nominal voltage are presented.

As it was stated before the dependence $W_{S H}\left(U_{B D}\right)$ follows the power law

$$
W_{S H}=a \cdot U_{B D}^{n},
$$

where $a$ and $n$ are the experimental parameters.

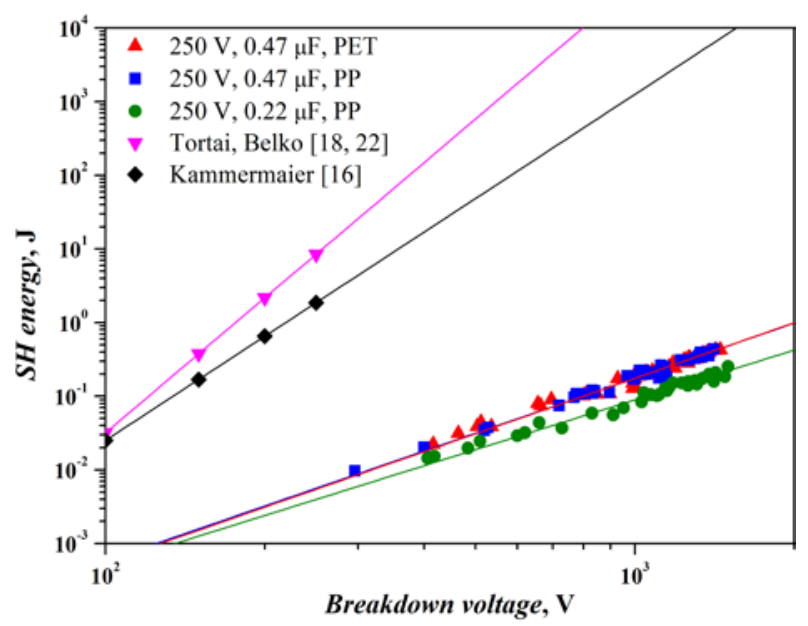

Fig. 5. Self-healing energy versus breakdown voltage

In current experiments with the real capacitors the exponent $n$ took values $=2.2-2.4$ that is a total disagreement with literature data (see Table 1) where the $n$ lies in the range of $4-6$ which seem to be overestimated. Indeed, extrapolating the literature $W_{S H}\left(U_{B D}\right)$ dependences to $1-2 \mathrm{kV}$ region one can see that $\mathrm{SH}$ energy reaches $10^{3}-10^{4} \mathrm{~J}$ values that is absolutely 
impossible in a real capacitor since this will surely cause the explosion of the device. Apparently, this disagreement is due to the fact that the previous investigations were made using model samples of MFCs, where the $\mathrm{SH}$ act was developing in unconfined conditions. In this case, the model experiment did not properly simulate the conditions of $\mathrm{SH}$ process in a real capacitor, where the free space is limited by the interlayer gap (commonly less than few microns), and energy and temporal characteristics of $\mathrm{SH}$ act are affected by interlayer pressure (up to 6-8 atm.). It is also important that the experimental dependences $W_{S H}\left(U_{B D}\right)$ are almost independent on polymer type of the capacitor.

\section{Conclusions}

The experimental method for investigation of $\mathrm{SH}$ processes in real metallized film capacitors was developed. Voltage and derivative current oscillograms can be obtained for energy and dynamic characteristics of $\mathrm{SH}$ process description.

The commercial PET and PP MFCs of $0.22-1 \mu \mathrm{F}$ capacitance and $63-250 \mathrm{~V}$ voltage were investigated. Depending on applied voltage 3 types of $\mathrm{SH}$ processes in MFC were observed: single $\mathrm{SH}$ (less than $3-4 U_{\text {nom }}$ ); repetitive $\mathrm{SH}\left(4-6 U_{\text {nom }}\right.$ ); multiple $\mathrm{SH}$ (more than 6 $U_{\text {nom }) \text {. }}$

Dependencies of SH energy on breakdown voltage were obtained. These dependencies are described by power law with the exponent $n=2.2-2.4$ that differs from literature data where $n$ reaches 6 or more. The difference is very significant and important since the dependency $W_{S H}\left(U_{B D}\right)$ serves as one of the basic principles for MFCs' degradation and aging laws formulation for energy storage capability improvement. The correct estimation of capacitor's reliability and lifetime is vital for applications with weight and space limitations where MFCs can be used in overstressed modes.

\section{Acknowledgements}

The research is supported by Russian Science Foundation (project № 19-79-10075).

\section{References}

1. O. A. Emel'yanov, Russ. Electr. Eng. 73, 6

2. K. Voloshin, Y. Bocharov, E. Gyulikhandanov, S. Sopozhnikov, E. Kolpishon, V. Barilovich, B. Matisov, G. Topazh, B. Lyamaev, and V. Nagornyy, in E3S Web Conf., 01006 (2019)

3. A. Refaat, M. Elgamal, and N. V. Korovkin, in Proc. 2019 IEEE Conf. Russ. Young Res. Electr. Electron. Eng. ElConRus 2019, 407-412 (2019)

4. A. B. Bekbaev, K. B. Shakenov, and V. V. Titkov, EAI Endorsed Trans. Energy Web 6, e5 (2019)
5. V. V. Titkov, A. B. Bekbayev, T. M. Munsyzbai, and K. B. Shakenov, Mag. Civ. Eng. 80, 171 (2018)

6. M. Makdessi, A. Sari, and P. Venet, Microelectron. Reliab. 54, 1823 (2014)

7. V. O. Belko and O. A. Emelyanov, J. Appl. Phys. 119, 024509 (2016)

8. H. Li, H. Li, Z. Li, F. Lin, D. Liu, W. Wang, B. Wang, and Z. Xu, Microelectron. Reliab. 55, 945 (2015)

9. M. Makdessi, A. Sari, G. Aubard, P. Venet, C. Joubert, and J. Duwattez, in 2015 IEEE 24th Int. Symp. Ind. Electron., 1296-1301 (2015)

10. H. Heywang, Colloid Polym. Sci. Kolloid Zeitschrift Zeitschrift Für Polym. 254, 139 (1976)

11. V. O. Belko, O. A. Emelyanov, I. O. Ivanov, and D. Y. Glivenko, in Proc. 2017 IEEE Russ. Sect. Young Res. Electr. Electron. Eng. Conf. ElConRus 2017, 1120-1122 (2017)

12. V. Belko, O. Emelyanov, and I. Ivanov, in Proc. 2016 IEEE Int. Conf. Dielectr. ICD 2016, 613-616 (2016)

13. Y. Fei, W. Zijian, and Y. Ting, J. Eng. 2019, 3371 (2019)

14. C. W. Reed and S. W. Cichanowski, IEEE Trans. Dielectr. Electr. Insul. 1, 904 (1994) (1966)

15. N. Klein, IEEE Trans. Electron Devices 13, 788

16. J. Kammermaier, IEEE Trans. Electr. Insul. EI22, 145 (1987)

17. J. Kammermaier, G. Rittmayer, and S. Birkle, J. Appl. Phys. 66, 1594 (1989)

18. J. H. Tortai, A. Denat, and N. Bonifaci, Conf. Electr. Insul. Dielectr. Phenom. (CEIDP), Annu. Rep. 2, 674 (2000)

19. J. H. Tortai, A. Denat, and N. Bonifaci, J. Electrostat. 53, 159 (2001)

20. B. Walgenwitz, J.-H. Tortai, N. Bonifaci, and A. Denat, in Proc. 2004 IEEE Int. Conf. Solid Dielectr. ICSD 2004, 29-32 (2004)

21. T. Christen and M. Carlen, Recent Res. Devel. Appl. Phys. 6, 517 (2003)

22. V. O. Bel'ko, P. N. Bondarenko, and O. A. Emel'Yanov, Russ. Electr. Eng. 78, 138 (2007) 